\title{
Experiências de médicos ao comunicarem o diagnóstico da deficiência de bebês aos pais
}

\section{Physicians' experiences when communicating the diagnosis of infants' disability to parents}

\author{
Valquíria Luisadaa, Geraldo A. Fiamenghi-Jrb, Sueli G. de Carvalhoc, Elisângela A. Assis-Madeirad, \\ Silvana M. Blascovi-Assis ${ }^{\mathrm{e}}$ \\ a Enfermeira. Mestre em Distúrbios do Desenvolvimento pela Universidade Presbiteriana Mackenzie. Docente no Centro Universitário \\ Faculdades Metropolitanas Unidas (FMU), São Paulo. \\ b Psicólogo. Doutor em Psicologia pela University of Edinburgh. Psicoterapeuta e Supervisor no CEPSI (Centro de Estudos em Psicologia), Itu, SP. \\ c Psicóloga. Doutora em Administração de Empresas pela Universidade Presbiteriana Mackenzie. Docente no Programa de Pós-Graduação em Distúrbios do \\ Desenvolvimento da Universidade Presbiteriana Mackenzie. \\ d Fisioterapeuta. Mestre em Distúrbios do Desenvolvimento pela Universidade Presbiteriana Mackenzie. Docente no Centro Universitário do \\ Leste de Minas Gerais (UNILESTE-MG) \\ e Fisioterapeuta. Doutora em Educação Física pela UNICAMP. Docente no Programa de Pós-Graduação em Distúrbios do Desenvolvimento da \\ Universidade Presbiteriana Mackenzie.
}

RESUMO

Objetivo: O presente estudo teve como objetivo investigar os sentimentos e vivências de médicos ao transmitirem a notícia de uma deficiência aos pais, no nascimento do bebê, assim como o preparo/formação que receberam para atuarem neste momento.

Material e Métodos: O estudo teve abordagem qualitativa e exploratória, a partir da técnica de entrevista semiestruturada. A pesquisa foi realizada com 10 médicos, entre Obstetras e Neonatologistas na cidade de São Paulo/ SP. As entrevistas foram analisadas e seus resultados discutidos em três diferentes categorias: a Notícia, Sentimentos e Preparo Profissional.

Resultados: Os médicos relatam dificuldades ao comunicar os pais sobre a deficiência dos bebês e pensam em estratégias variadas, como falar ao casal; falar apenas para a mãe, falar imediatamente após o parto, esperar algum tempo; revelam tristeza e inexistência de preparo durante a formação em medicina.

Conclusão: Foram sinalizadas abordagens inadequadas e ineficazes, e o despreparo e dificuldades na comunicação da notícia, associados à falta de formação acadêmica para desempenhar esta tarefa. Conclui-se que os principais sentimentos vivenciados são a tristeza, a angústia e a solidariedade, com consequências físicas e emocionais para o profissional e, provavelmente, para a família dos pacientes.

Palavras-chave: diagnóstico; bebês com deficiência; emoções; relações médico-paciente.

Objective: This study aimed to investigate the feelings and experiences of physicians when breaking the news of a disability to parents, at the child's birth, as well as the skills and qualifications to perform that task.

Material and Methods: The qualitative exploratory study used a semi-structured interview. Research was conducted with 10 physicians, obstetricians and neonatologists in São Paulo. Interviews were analyzed and results discussed using three different categories: News, Feelings, and Professional Qualification.

Results: Physicians report difficulties in communicating the parents about their infants' disabilities and think on different strategies, such as talking to the couple, talking to the mother only; talking immediately after birth, waiting for some time before breaking the news; refer sadness and lack of training while in medical studies.

Conclusion: Inadequate and inefficient approaches were pointed, as well as the lack of skills and difficulties in communicating the news, associated to nonexistence of academic qualification to complete those duties. It is concluded that the main feelings are sadness, anxiety and solidarity, with physical and emotional consequences for the professional, as well as to their parents' families.

Keywords: diagnosis; disabled infants; emotions; physician-patient relations. 


\section{INTRODUÇÃO}

A chegada de um filho encontra-se entre os acontecimentos significativos que marcam uma importante mudança de ciclo no desenvolvimento familiar; acontecimento normal, mas vai demandar ao casal e da família mecanismos de ajuste para incorporar e enfrentar a nova situação, provocando alterações na dinâmica familiar ${ }^{1}$. Todo este mecanismo é potencializado com a inclusão de um filho deficiente, com problemas de saúde, ou necessidade especial, afetando assim esta dinâmica. O momento e a forma como o diagnóstico é informado à família são aspectos relevantes que vão interferir no processo de adaptação familiar. Os problemas e anseios que os pais vivenciam decorrem de informações tardias, erradas e incompletas. Sendo assim, é prioritária a conscientização precoce sobre o diagnóstico.

Aparentemente, todos os pais vivenciam o choque e o medo com relação à notícia, bem como a dor e a ansiedade de se pensar nas expectativas para o futuro dessa criança ${ }^{2}$. O período gestacional em si já é acompanhado por sonhos, imaginação, anseios e expectativas, e o encontro com a realidade, muitas vezes difícil, é o momento do parto, confronto este intensificado pela ansiedade do próprio procedimento ${ }^{3}$.

É importante refletir sobre o papel do profissional da saúde na assistência ao parto de uma criança deficiente ${ }^{4}$. Importante considerar o fator surpresa, e que poucos pais sabem receber a notícia, assim como poucos profissionais sabem dá-la. A intensidade da situação envolve complexa e imprevisível repercussão no contexto familiar. A dificuldade em noticiar a deficiência e seu impacto deixará marcas significativas nos familiares, em especial nos pais do recémnascido com deficiência, por estarem envolvidos diretamente com a situação ${ }^{3}$.

Os profissionais responsáveis pela comunicação da notícia devem ter preparo e preocupação com este momento sutil na vida das famílias, visando diminuir o trauma, para que possam superar o momento e conseguir dar continuidade para o desenvolvimento adequado da criança.

Pesquisas mostram que se a notícia difícil é comunicada inadequadamente, pode causar confusão, angústia prolongada e ressentimentos na família. Feita de forma adequada pode ajudar na compreensão, aceitação e adaptação. A comunicação eficaz tem seus benefícios comprovados como qualidade da coleta de informações, melhor recuperação do paciente, adesão aos planos de tratamento, resultando em melhores resultados para os pacientes, maior satisfação com as consultas, melhora na segurança e redução de queixas ${ }^{5,6}$.

Na mesma linha, deve-se ressaltar a importância de um momento para esclarecimento de dúvidas, orientações, apoio psicológico para que sejam superados os sentimentos negativos que são potenciais para posteriores dificuldades ${ }^{3}$. A equipe multidisciplinar deve estar preparada para lidar com angústias, dando suporte à família neste momento difícil, fornecendo orientações e encaminhamentos específicos, a cada caso, para melhor atender às necessidades de cada família.

As dificuldades no comportamento dos médicos, na dimensão sócio emocional do cuidado com o paciente, são reconhecidas pelo público e pela própria comunidade médica ${ }^{7}$. Muitos médicos têm dificuldades em lidar com suas próprias emoções como tristeza, culpa, identificação e sentimento de fracasso. Há pouca evidência de que estas dificuldades sejam atenuadas com o aumento da experiência profissional. A formação insuficiente em habilidades de comunicação é reconhecida por médicos experientes como um fator importante que contribui para uma morbidade psicológica 5 . Assim, esta pesquisa teve o objetivo de descrever os sentimentos e vivências dos médicos na comunicação do diagnóstico de deficiência aos pais de crianças recémnascidas.

\section{MATERIAIS E MÉTODOS}

Tratou-se de um estudo exploratório descritivo, de caráter qualitativo. Participaram do estudo quatro médicos e seis médicas, entre obstetras e neonatologistas, com mais de cinco anos de formação profissional, recrutados em hospitais e maternidades localizadas na cidade de São Paulo/SP, que confrontam em seu cotidiano com a necessidade de dar aos pais a notícia de deficiência de um recém-nascido e que concordaram em participar da pesquisa. Como critérios de inclusão, foram considerados: ter graduação em medicina com especialização em neonatologia e/ou obstetrícia, atuar no serviço de atenção à saúde materno infantil, no mínimo, há cinco anos, e ter comunicado a, pelo menos, uma família, o diagnóstico de deficiência diagnosticada no período perinatal.

Utilizou-se a técnica de entrevista semiestruturada, com o intuito de se compreender a percepção dos participantes em relação ao momento da notícia da deficiência, com destaque às questões com referência ao preparo profissional e sentimentos gerados por tal situação.

O projeto de pesquisa foi aprovado pelo Comitê de Ética da Universidade (UPM, 058970/2012). A Carta de Informação aos Sujeitos de Pesquisa foi apresentada e, após o consentimento, foram agendadas as datas para a realização das entrevistas, como também foi ressaltado o compromisso de se realizar as devolutivas aos participantes do estudo.

Os consultórios médicos foram os locais escolhidos para a realização das entrevistas, pois propiciavam privacidade 
e, ainda, a facilidade de agendamento prévio com data e hora determinada, de acordo com a disponibilidade dos entrevistados.

A técnica utilizada para a sistematização dos dados foi a análise de categorias ${ }^{8}$. Após a leitura das transcrições literais das entrevistas gravadas, foram criadas três categorias e, cada uma delas, divididas em duas subcategorias. Os relatos dos médicos estão apresentados na sequência em cada uma das três categorias identificadas e as respectivas subcategorias. Os profissionais tiveram o anonimato preservado e seus relatos estão representados por números, sendo o profissional número 1 representado por $\mathrm{P} 1$, e assim sucessivamente, até o P10.

\section{RESULTADOS E DISCUSSÃO}

As entrevistas foram gravadas, com a anuência dos entrevistados e duraram, em média, 40 minutos.

Em relação aos diagnósticos de base, estes não foram especificados, pois os médicos mencionaram suas experiências de forma espontânea, sem referir-se quais categorias de deficiências estavam exemplificando. Serão apresentados abaixo, os resultados e discussões em cada categoria e subcategoria, exemplificados com falas dos participantes.

\section{CATEGoria 1: A Notícia}

\section{1a: Notícia aos Pais}

A transmissão de notícias difíceis é uma tarefa complexa, pois, além do componente verbal de comunicar, de fato, a tarefa também requer outras habilidades, tais como, responder às reações emocionais dos familiares, manejar o estresse criado pelas expectativas, trabalhar com a capacidade de decisão dos pais e o envolvimento e participação de múltiplos membros da família, incluindo o dilema de como dar esperança quando a situação é sombria ${ }^{9}$. De acordo com esse cenário, os participantes da pesquisa foram questionados sobre como abordam a notícia da deficiência do recém-nascido aos pais e qual o melhor momento para essa abordagem. Destacam-se relatos de alguns profissionais:

O momento do nascimento, não é o melhor momento para falar, desde que não seja uma "coisa" já conhecida e que não seja incompatível com a vida. (P9)

Todas as vezes que tem uma má formação, eu chamo o pai, primeiro, junto com o pediatra e comunico, no dia seguinte, eu falo com a mãe... (P2)

Acho que é importante você falar na sala de parto para o pai, para não ser uma coisa que seja omitida. (...) Para a mãe, a gente costuma falar depois que ela já viu o bebê... (P7)
No momento do nascimento... eu acho que a primeira coisa é não dar nomes, porque na verdade não sabemos o diagnóstico, mesmo que tenha uma suspeita muito grande (...) na hora da mãe ir ver o bebe, vai, põe o bebê no colo, toca, se possível amamenta, tem um primeiro vínculo, e aí sim você fala (...) o importante é você ter o vinculo primeiro e aí depois você da a informação o mais rápido possível... (P4)

O quanto antes, esperar a mãe sair da sala de parto, chegar ao quarto, os pais sozinhos, e é comunicado. (...) quanto mais tempo passar cria aquela angústia para os profissionais de saúde em transmitir a notícia, (...), eu acho que demora mais ainda para os pais a aceitação deste fato. (P5)

Normalmente na hora do parto o neonatologista tem uma suspeita, e ele costuma confirmar através de um cariótipo, (...). Então, na medida em que se confirma, o que acontece de um a dois dias após o parto, é o momento de você conversar. (P6)

Observou-se que a maioria dos profissionais entende que a notícia da deficiência deve ser deixada para um segundo momento, não devendo ser abordada no momento do parto, que é compatível com a opinião dos pesquisadores, quando registram não ser a hora do nascimento o momento adequado para se noticiar a deficiência ${ }^{5,10,12}$. Por outro lado, P5 entende que a notícia deve ser transmitida o quanto antes, justificando que a demora na notificação aumentaria o sentimento de angústia para os profissionais responsáveis pela informação, assim como favoreceria o processo de aceitação para o casal. Pesquisadores salientam que quando as circunstâncias não seguem o padrão esperado, a experiência pode ser extremamente estressante e angustiante para todos os envolvidos ${ }^{5,11}$.

Os relatos de P4, P5 e P6 apontam para a necessidade de o casal estar junto no momento da notificação, inicialmente informando parcialmente, sem dar um diagnóstico preciso, sugerindo apenas uma suspeita e a necessidade de se aguardar os resultados de exames diagnósticos para uma informação mais completa e precisa. Estas condutas coincidem com a orientação de diferentes autores $5,6,12,13$.

Os médicos entrevistados ressaltaram a importância da formação de um vínculo afetivo entre a mãe e o bebê, prévio à notificação, como exemplo, têm-se os trechos dos relatos de P4 e P8, dando, assim, a oportunidade para mãe estabelecer contato com a criança sempre que possível. Estas informações vão ao encontro das orientações proferidas por alguns pesquisadore ${ }^{10}$. Por outro lado, P2 e P7 ressaltaram a preocupação em informar ao pai ou algum outro familiar imediatamente após o nascimento, antes da mãe, pois a demora da notícia pode implicar em que os familiares considerem que o médico tenha omitido a informação. 
Estudos $^{14}$ chamam a atenção para a amplitude do desdobramento do tema comunicação de notícias difíceis na área da saúde. Tal comunicação deve envolver, também, aspectos da bioética com implicações jurídicas, cuja inobservância pode gerar demandas por negligência, imperícia ou imprudência, como consequência de informações truncadas ou mal colocadas.

\section{1b: Especialidade Médica}

Não foram encontrados na literatura, até o presente momento, dados que apontem a preferência dos pais por um ou outro profissional para a abordagem da notícia de uma possível deficiência do recém-nascido. A literatura preconiza a abordagem multiprofissional ${ }^{15,16}$. Desta forma, os participantes da presente pesquisa foram questionados sobre as respectivas opiniões em relação a quais profissionais deveriam comunicar a má notícia à família.

No momento do parto a mãe confia mais no obstetra do que no próprio pediatra... (P5)

Acho que ambos... talvez o 'neo' [neonatologista] num primeiro momento, mas o obstetra precisa dar um reforço. (P8)

Na sala de parto acho que fica com o neonatologista, para falar com os pais, com o pai, (...) Mas na hora em que a noticia tem que ser dada para a mãe, o obstetra que acompanhou o pré-natal e tudo, acho que ele deveria estar junto, (...) é o médico que a mãe está tendo mais contato, que ela tem uma credibilidade e uma confiança maior. (P7)

A responsabilidade de informar é do pediatra, que é quem está examinando a criança, quem vai cuidar de dar o diagnóstico e o tratamento. Mas, como o obstetra tem uma relação longa já com os pais, ele é uma pessoa que pode ser um grande facilitador. (P4)

Num primeiro momento, o profissional que tem que abordar esta notícia é mesmo o obstetra, (...) o obstetra tem que ter pelo menos o mínimo de preparo para lidar com esta situação. (P1)

Os médicos (P4, P7 e P8) consideram que a notícia da deficiência deve ser abordada pelos obstetras e neonatologistas, de preferência juntos. Ressaltaram que embora o neonatologista seja tecnicamente o responsável, pois é quem examina, avalia, presta os primeiros cuidados, faz o diagnóstico e determina o tratamento, é o obstetra, que na maioria dos casos, é o profissional que o casal já conhece, usufruindo de maior credibilidade pela confiança adquirida ao longo do acompanhamento da gestação e do parto. Porém, P1 e P5 entendem que deve ser o obstetra o profissional responsável pela abordagem desde o primeiro momento.
Não há, segundo as pesquisas, consenso sobre qual especialista seria o responsável por dar a notícia da deficiência do bebê aos pais, 6,9,14. Consequentemente, a comunicação vai depender, em parte, do envolvimento do médico e de sua percepção acerca das possibilidades em lidar com a situação.

\section{CATEGORIA 2: Sentimentos}

\section{2a: Familiares}

Os relatos dos profissionais entrevistados deram ênfase ao sentimento de negação em primeiro plano, quando foram perguntados sobre como os familiares costumam reagir com a notícia de deficiência de seu filho, além de ressaltarem outros sentimentos como tristeza, surpresa, frustração e inconformismo, exemplificados pelos trechos das respostas de P3, P4, P6, P7 e P8:

Eles reagem com o silêncio, (...) depois é que começam a pesquisar, (...) e aí surgem as milhões de dúvidas e o medo do futuro. (P3)

Eles têm uma esperança de que não seja nada disso, e que você percebe que por mais que eles tenham a informação, eles estão lá, pensando, 'não vai ser'. (P4)

No momento, no inicio é a tristeza, é a frustração, mas depois vem a aceitação, pelo fato de você estimular carinho e amor, daquele ser que depende somente deles para poder crescer. (P6)

O primeiro sentimento é de negação. É perguntar da certeza, (...) qual é a chance. (P7)

Acho que surpresos, às vezes, inconformados e às vezes com negação... (P8)

Pode-se perceber que P3 apontou o silêncio como primeira reação dos pais diante da notícia da deficiência, talvez, como demonstração de surpresa, por não conseguir expressar seus sentimentos naquele difícil momento. De acordo com a literatura, as reações emocionais dos pais podem variar do silêncio à incredulidade, choro, negação ou raiva. Quando os familiares ouvem más notícias, suas reações emocionais mais frequentes são expressões de choque, isolamento e dor $3,5,9,10,19$.

Os pais passam por estágios progressivos de sentimentos como negação, choque, culpa, raiva, tristeza, depressão, ansiedade e reduzida autoestima, sinalizados em sequências e intensidade diferentes, conforme a família ${ }^{12}$. A reação dos pais depende de fatores como personalidade, crenças religiosas, apoio familiar e contexto cultural em que vivem, e nem sempre o médico conhece as características da família antes de comunicar uma má notícia ${ }^{17}$. Em casos de negação os pais tentam ignorar os sintomas, tratando a criança como 'normal'12. 
As más notícias têm graduações, até certo ponto, subjetivas, dependendo das experiências de vida de cada indivíduo, das suas expectativas, personalidade, crenças espirituais, ponto de vista filosófico, conhecimento de grupos sociais de apoio e robustez emocional. Choque, horror, raiva, negação, aceitação estoica e descrença são as reações possíveis e esperadas, e qualquer pessoa incumbida de fornecer uma notícia difícil precisa ser capaz de lidar com estas emoções. Portanto, entender o que é importante para os pacientes quando a notícia triste ou perturbadora é dada, pode ajudar os médicos a redefinirem a melhor forma de como esta tarefa deverá ser feita ${ }^{5}$.

Os pais precisam de tempo para aceitar a notícia como um termo médico e não como uma reprovação de cunho pessoal. Eles tendem a negar o diagnóstico mesmo após a confirmação, nestes casos, alguns autores ${ }^{12,13}$ sugerem a solicitação de outro teste para que se tenha, com precisão, a confirmação.

Os pais, muitas vezes, se culpam por atribuírem a deficiência a atitudes e atos culturalmente impróprios durante a gestação como esforço físico, viagens e outros, ou mesmo culpando as mães quando o transtorno envolve o cromossomo $\mathrm{X}$, e ou o cromossomo $\mathrm{Y}$, no caso da responsabilidade recair sobre o pai. Nestes casos a orientação médica deve ser dirigida na explicação das causas genéticas e ou inevitáveis. Deve-se inclusive incentivá-los a procurar uma segunda opinião, encaminhá-los a especialistas específicos, mostrando sua preocupação e fornecendo este suporte inicial. A negação muitas vezes pode bloquear a jornada emocional do casal, ou mesmo direcioná-los a terapias exóticas e onerosas que prometem a cura, mas depois decepcionam ${ }^{12}$.

Uma das tarefas mais difíceis é reagir às emoções dos pacientes e familiares. Muitas vezes, os médicos não são capazes de responder adequadamente aos sentimentos expressos por eles, ou até mesmo identificá-los. Emoções comuns, como medo ou desgosto, podem ser interpretadas com raiva contra o próprio médico, não sendo incomuns situações difíceis envolvendo familiares ${ }^{17}$.

\section{2b: Profissionais}

Diante da questão abordando os sentimentos do profissional no momento do relato da notícia de deficiência aos pais, os 10 entrevistados alegaram dificuldades para a abordagem, pois a consideram muito desagradável e, ainda, responsável por gerar inúmeros e complexos sentimentos no profissional incumbido desta notificação. Tristeza foi o sentimento de maior ocorrência, seguido por angústia, sofrimento pelo outro, solidariedade, frustração e até incerteza. Parte desses relatos seguem na sequência:
Eu tento ser o mais natural possível, mas é superdifícil, porque a gente já vai pensando em como os pais vão reagir, dependendo da maneira como os pais reagem, eu me sinto um pouco pressionado, em tentar mostrar cenários favoráveis, de tentar minimizar o problema para os pais. (P5)

Tristeza, tristeza também de não poder dar uma boa notícia. (P6)

Você acaba tomando o sentimento para si, um pouco, (...) você sempre se põe no lugar, (...), e se fosse com alguém da minha família, e isso também acaba atrapalhando um pouco. (P7)

Você tem que ser frio, falar, e ficar quieto. Você só comunica, (...) de uma forma delicada, mais amorosa, (...), é lógico, que você fica muito triste, muito magoado, é como se fosse um filho seu (...) Faz muito mal (...). É extremamente estressante, preocupante, desgasta demais a gente, que até envelhece. (P2)

O sentimento é de tristeza, angústia, (...) a dor e a angustia de ter que falar, é muito ruim, mesmo sabendo que independe de você. (P10)

Você tem sentimentos de tristeza, sentimentos de pena, de incerteza, é, eu acho que são sentimentos que qualquer ser humano tem em relação a esta situação. (P1)

Você fica (...) chateada, porque é um momento de nascimento, (...), e eu me valho muito de espiritualidade. (P9)

É muito frustrante ter que dar uma notícia dessas, é muito difícil lidar com esta expectativa. (P3)

Nota-se nos relatos dos entrevistados sentimentos de tristeza, angústia, chateação, estresse, pressão, incerteza e frustração, além de sentimentos de se colocar no lugar do outro.

Vários experimentos psicológicos mostraram que o profissional que 'carrega' a má notícia, frequentemente experimenta emoções fortes, como ansiedade, uma carga de responsabilidade pela notícia ${ }^{9}$, como relata $\mathrm{P} 3$, e o medo de uma avaliação negativa, como descreve P5. Os autores também alegam que este estresse cria uma relutância na transmissão das más notícias.

O médico é questionado constantemente na escolha do melhor caminho para uma possível cura ou estabilização de um estado de doença. Mesmo contemplado por uma aura de infalibilidade, o profissional estará sujeito a incertezas e insegurança sobre a melhor conduta diante de um quadro clínico desafiador ${ }^{14}$.

O participante P5, após alegar excessiva dificuldade, explicou que pensa, antecipadamente, em quais seriam as reações dos pais, e referiu se sentir também pressionado dependendo das reações encontradas. Esta afirmação 
coincide com os resultados encontrados por estudos ${ }^{5}$ em que a maioria dos médicos pesquisados informa preocupação com a imprevisibilidade de reação dos pacientes com a notícia ruim.

No contexto médico, a comunicação de más notícias é um processo estressante tanto para o paciente quanto para o médico. Estudos mostram que, antes de informar aos familiares, o médico vive um estresse antecipatório, medo, ansiedade e, ainda, a incerteza em relação às possíveis reações que os pacientes possam apresentar ${ }^{18}$.

Espera-se que o médico sempre saiba lidar com suas próprias emoções e receios, porém, grande parte de profissionais pondera que não recebeu treinamento formal durante as respectivas formações no sentido de the propiciarem segurança na comunicação de más notícias ${ }^{17}$.

No relato de P2, destaca-se o trecho em que ele reconhece que estes sentimentos o prejudicam física e psicologicamente, com alegações como "faz muito mal" e "até envelhece", assim como apontado pelos resultados do inquérito realizado por Baile et a ${ }^{9}$ que demonstram que tal desconforto pode levar os profissionais ao estresse.

\section{Categoria 3: Preparo Profissional}

\section{3a: Formação Acadêmica}

De acordo com as informações coletadas, a maioria dos entrevistados reconhece que não teve preparo para a abordagem da má notícia durante seus cursos de formação profissional em Medicina, e nem mesmo durante o período de residência médica, como demonstram os seguintes trechos:

Na prática sim, na teoria não. Na prática, eu aprendi com meus professores, de vê-los fazendo, mas nunca tive uma aula sobre isso, nunca tive! (P3)

Eu tive dois anos de aulas de psicologia, (...) tinham algumas aulas em que o tema era esse. Mas acaba aprendendo mesmo é na prática. (P7)

Durante a Faculdade de Medicina não, e mesmo durante a residência também não. Isto foi acontecendo com a vida (...). (P9)

Não temos um preparo formal para isso, (...) é no plantão que a gente pega um caso e dá a sorte de estar com um professor que é bom nisso, age de uma forma que vai ter um desfecho feliz e a gente aprende que deve ser desta forma que se deve abordar, (...). (P4)

Muito pouco, na faculdade, foi uma leve "pincelada" que não serviu prá nada, na prática mesmo é o dia à dia de convivência, é a prática clínica mesmo. (P5)

Não, não, tive um curso de psicologia médica que durou umas quatro semanas, no quarto ano, que é quando você nem tem noção, não é? (P8)
Percebe-se que alguns entrevistados, como exemplos P5, P7 e P8, referiram ter tido alguma explanação muito breve e superficial, alegando que da forma como ocorreu, não houve aproveitamento. Os profissionais P7 e P5 explicaram que, quando ocorreram as citadas aulas, por volta do quarto ano do ensino médico, a falta de experiência profissional e do contato real com os pacientes, resultou em que o conteúdo não fosse assimilado.

Neste ponto, as alegações dos participantes P7 e P5 correspondem às impressões de outras pesquisas ${ }^{17}$, pois questionam a abordagem deste assunto em um momento considerado prematuro na carreira médica. Os estudantes estão ainda longe do contato mais próximo e continuado com pacientes, o que só ocorre, na maioria dos currículos no Brasil, nos últimos dois anos. No entanto, entendem contrariamente à opinião de nossos participantes, que uma abordagem precoce é desejada por procurar discutir o assunto antes que o aluno se encontre em situação similar e despreparado para tal abordagem. Consideram que os alunos teriam a oportunidade de reflexão sobre as situações vivenciadas em aulas práticas, estágios e até mesmo em experiências pessoais ou com familiares.

De modo geral, parte dos programas de graduação e pós-graduação médica não oferece treinamento específico para a transmissão de más notícias e a maior parte dos médicos aprende a dar notícias pela observação de colegas mais experientes em situações de vivência diária9,18. Os relatos de P3, P4 e P9 exemplificam a opinião da maioria dos entrevistados, para os quais o aprendizado ocorreu com a prática profissional, no 'dia-a-dia', alguns por presenciar os erros e acertos observados e vivenciados no período da residência médica.

Em uma pesquisa realizada ${ }^{9}$ quase $40 \%$ dos respondentes não apenas não tiveram treinamento didático, como também não tiveram oportunidade de adquirir experiência pela observação de outros médicos transmitindo más notícias. Relatam a falta de confiança em sua capacitação para esta tarefa. Os autores também discutem que as orientações atuais das Sociedades Médicas Americanas ainda não incluem recomendações para o treinamento em habilidades essenciais de comunicação.

Uma urgente reformulação no paradigma curricular dos cursos médicos com adoção de um eixo cognitivo espiritual, versatilidade e transversalização, inclusive para melhorar o conhecimento e diminuir o estresse profissional. Em nossa realidade universitária, esse ideário humanista ainda está longe de ser alcançado no conteúdo curricular integrado, e que na ausência dessas práticas, "as lacunas decorrentes das suas distorções ecoam pelas enfermarias e pelos ambulatórios e consultórios mundo afora"14 (p. 17). 


\section{3b: Dificuldades dos Profissionais}

Quando foram indagados se apresentavam dificuldades na comunicação de más notícias, P1 e P10 responderam que não existe essa dificuldade, porém, P2, P4, P5 e P7 disseram que a dificuldade existe sim, alegando diversos motivos, exemplificados a seguir.

Sinceramente não, talvez porque na minha formação, antes de escolher obstetrícia, eu trabalhei por muito tempo com psiquiatria (...), é o que me dá um certo conhecimento, até para lidar com esta situação de uma forma mais tranquila hoje. (P1)

Olha, eu nunca encontrei este tipo de dificuldade. Porque é uma coisa que independe de qualquer um. (...) Você vai abordar um assunto que tem que ser abordado. (P10)

Dificuldade é a dificuldade emocional. Não é fácil você dar uma notícia para uma mãe. (P2)

Dificuldade é o sofrimento, é saber que você esta de posse de uma informação, que você tem que dar. (P4)

Acho que todo mundo encontra. Dar notícia boa, acho que todo mundo sabe fazer é super prazeroso, agora, abordar uma patologia, uma má evolução do paciente, uma piora, ou uma síndrome é super complicado. (P5)

Você não sabe como a mãe vai reagir, depende também da credibilidade, geralmente o neonatologista não é o médico que a mãe já conheça. (P7)

Quando se focam os relatos dos profissionais, identificamse dificuldades variadas na abordagem da deficiência aos pais, tais como, dificuldade pelo fato da notícia ser ruim, temor pela reação dos pais associada à falta de credibilidade, por ser um profissional ainda sem contato e vínculo com estes pais, dificuldade principalmente nas patologias e quadros mais severos e até motivos profissionais, onde uma categoria tenta se eximir de uma provável responsabilidade pela não antecipação de um diagnóstico.

Um erro comum é encarar o processo da má notícia como um sentimento de fracasso ou até de culpa. O profissional deve tentar entender os próprios sentimentos evocados no momento em que comunica notícias difíceis. Enfrentando os seus medos, ansiedades e aprendendo a reconhecê-los e controlá-los, o médico se sentirá mais à vontade diante das reações dos pais, inclusive podendo ajudá-los da melhor maneira possível ${ }^{17}$.

A informação de notícias ruins, difíceis e tristes sempre será uma parte desagradável, mas necessária da medicina. Diversos estudos $5,6,19,14$ indicam que os estudantes de medicina devem aprender sobre os aspectos relacionais e humanistas da comunicação.

Tentando auxiliar os aspectos em questão, foi desenvolvido o protocolo SPIKES, cujo objetivo é o de habilitar o médico a preencher os quatro objetivos mais importantes da entrevista de transmissão de más notícias: recolher informações dos pacientes, transmitir as informações médicas, proporcionar suporte ao paciente e induzir a sua colaboração no desenvolvimento de uma estratégia ou plano de tratamento para o futuro. Médicos e estudantes a quem o protocolo foi ensinado relataram aumento da confiança em suas habilidades para transmitir informações médicas desfavoráveis ${ }^{9}$.

Pesquisa realizada com objetivo de se avaliar a utilização do protocolo SPIKES no Brasil ${ }^{17}$ considerou o modelo válido, mesmo levando-se em conta possíveis limitações, como a necessidade de ser individualizado e adaptado às diferentes situações. Os pesquisadores acreditam que por reconhecerem a transmissão de más notícias uma tarefa estressante, que está presente em alguns momentos da atuação profissional, muitos médicos a evitam ou a comunicam de maneira inadequada. $\mathrm{E}$ embora seja objeto de estudo em diversos cursos de Medicina em nível internacional, o tema ainda é pouco explorado por professores e estudantes no contexto brasileiro.

A necessidade de integrar uma comunicação didática adequada ao ensino de graduação e pós-graduação de medicina tem sido reconhecida como uma relevante necessidade nesta última década. A formação de profissionais de saúde preparados para esta tarefa, de forma mais eficaz, produzirá benefícios para os mesmos, assim como para seus pacientes, e o treinamento deve ser baseado em princípios educacionais, em evidências, avaliado e monitorado adequadamente ${ }^{5}$.

\section{CONSIDERAÇÕES FINAIS}

O presente estudo teve origem na proposta de caracterização da visão e sentimentos dos médicos a respeito da notificação da deficiência aos pais por ocasião do nascimento, com base na realidade dos participantes entrevistados nesta pesquisa. Uma limitação importante para a pesquisa refere-se ao número reduzido de participantes. Apesar de que a maioria das respostas tenha tido um padrão comum, talvez um maior número de participantes pudesse proporcionar maior diversidade nos resultados.

Conclui-se que o principal sentimento vivenciado pelos médicos, nesse momento peculiar, é a tristeza. Outros sentimentos foram detectados como a angústia e a solidariedade, a frustração foi igualmente mencionada, talvez, pelo fato do sentimento de impotência diante do diagnóstico de deficiência e a incerteza do prognóstico da criança. Esses sentimentos têm consequências físicas e emocionais para o profissional transmissor da notícia.

Outro aspecto a ser ressaltado é a inadequação e quase inexistência de preparo acadêmico para a comunicação 
de notícias difíceis/más/negativas. A maior parte dos médicos entrevistados declarou não ter em seus cursos de graduação, e mesmo pós-graduação, qualquer preparo para a comunicação do diagnóstico da deficiência do bebê aos pais, ou mesmo da comunicação de qualquer outra notícia ruim. Os poucos participantes que referiram ter tido alguma abordagem relataram que foi inadequada e ineficaz. Desta forma, a ausência de conhecimentos aliada à escassez de preparo em relação à abordagem da notícia da deficiência revelou-se, pelos profissionais, como sendo uma relevante dificuldade. Estar convencido de que os familiares têm direito à informação, como relataram alguns participantes, não garantirá que a informação seja transmitida adequadamente. Os médicos descreveram algumas reações da família no momento da notícia, por exemplo, negação, tristeza e silêncio. Contudo, tais reações são incertas e dependem de muitos fatores, como expectativas da família, traços de personalidade de quem recebe a notícia e até de crenças espirituais.

Sugere-se para as próximas pesquisas, como uma complementação da temática de abordagem da notícia da deficiência aos pais por ocasião do nascimento do bebê, estudos que se aprofundem na relação mãe-bebê, no vínculo emocional a ser estabelecido, e no ato de amamentar como um aspecto de contribuição para a assimilação da má notícia.

\section{REFERÊNCIAS}

1. Fiamenghi-Jr GA, Messa AA. Pais, filhos e deficiência: estudos sobre as relações familiares. Psicol Ciênc Prof. 2007; 27(2):236-245. http://dx.doi.org/10.1590/S1414-98932007000200006

2. Vash CL. Enfrentando a deficiência: a manifestação, a psicologia, a reabilitação. São Paulo: Pioneira; 1988.

3. Cunha MAFV, Blascovi-Assis SM, Fiamenghi-Jr GA. Impacto da notícia da síndrome de Down para os pais: histórias de vida. Ciênc. Saúde Coletiva. 2010; 15(2):444-451. http://dx.doi.org/10.1590/ s1413-81232010000200021

4. Falkenbach AP, Drexsler G, Werler V. A relação mãe/criança com deficiência: sentimentos e experiências. Ciênc. Saúde Coletiva. 2008; 13:(2):2065-2073. http://dx.doi.org/10.1590/S141381232008000900011

5. Fallowfield L, Jenkins V. Communicating sad, bad, and difficult news in medicine. Lancet. 2004; 19:363-312. http://dx.doi.org/10.1016/ s0140-6736(03)15392-5
6. Hammond M, McLean E. What parents and carers think medical students should be learning about communication with children and families. Patient Educ Couns. 2009; 76:368-375. http://dx.doi. org/10.1016/j.pec.2009.07.020

7. Carmel S, Glick SM. Compassionate empathic physicians: personality traits and social organizational factors that enhance or inhibit this behavior pattern. Soc Sci Med. 1996; 43(8):1253-1261. http:// dx.doi.org/10.1016/0277-9536(95)00445-9

8. Bardin L. Análise de conteúdo. Lisboa: Edições 70; 2000.

9. Baile WF, Buckman R, Lenzi R, Glober G, Beale EA, Kudelka AP. SPIKES: a six-step protocol for delivering bad news: application to the patient with cancer. Oncologist. 2000; 5:302-311. http://dx.doi. org/10.1634/theoncologist.5-4-302

10. Sunelaitis CR, Arruda DC, Marcom SS. A repercussão de um diagnóstico de síndrome de Down no cotidiano familiar: perspectiva da mãe. Acta Paul Enferm. 2007; 20(3):264-271. http://dx.doi. org/10.1590/S0103-21002007000300004

11. Jurkovich GJ, Pierce B, Pananen L, Rivara FP. Giving bad news: the family perspective. J Trauma. 2000; 48(5):865-873. http://dx.doi. org/10.1097/00005373-200005000-00009

12. Golder WN. When you must give a baby's parents terrible news. Med. Econ. 1996; 73(3):247.

13. Farrel MH, La Pean A, Ladouceur I. Content of communication by pediatric residents after newborn genetic screening. Pediatrics. 2005; 116:1492-1498. http://dx.doi.org/10.1542/peds.2004-2611

14. Perdicaris AME. E agora doutor?: velhos caminhos e novas fronteiras na comunicação médica. $2^{\underline{a}}$ ed. rev. Barueri (SP): Minha Editora/ Manole; 2012

15. Ministério da Saúde (BR). Instituto Nacional do Câncer. Comunicação de notícias difíceis: compartilhando desafios na atenção à saúde. Rio de Janeiro: INCA, 2010.

16. Ceccim RB. Equipe de saúde: a perspectiva entre-disciplinar na produção de atos terapêuticos. In: Pinheiro R, Mattos RA, organizadores. Cuidado: as fronteiras da integralidade. São Paulo: Hucitec/Abrasco; 2004.

17. Lino CA, Augusto KL, Oliveira RAS, Feitosa LB, Caprara A. Uso do protocolo SPIKES no ensino de habilidades em transmissão de más notícias. Rev Bras Educ Med. 2011; 35(1):52-57. http://dx.doi. org/10.1590/S0100-55022011000100008

18. Perosa GB, Ranzani PM. Capacitação do médico para comunicar más notícias à criança. Rev Bras Educ Med. 2008; 32(4):468-473. http://dx.doi.org/10.1590/S0100-55022008000400009

19. Pupo Filho RA. Síndrome de Down. E agora doutor? Rio de Janeiro: WVA; 1996. 